\title{
Jefferson.
}

JHN Journal

Volume $11 \mid$ Issue 1

Article 3

Winter 2016

\section{Managing Hyperglycemia in Critically Ill Patients: Where are We Now?}

\author{
Umer Shoukat, MD \\ Department of Neurological Surgery, Thomas Jefferson University, umer.shoukat@jefferson.edu \\ Umer Mukhtar, MD \\ Department of Neurological Surgery, Thomas Jefferson University, umer.mukhtar@jefferson.edu \\ M. Kamran Athar, MD \\ Department of Medicine, Thomas Jefferson University, kamran.athar@jefferson.edu
}

Follow this and additional works at: https://jdc.jefferson.edu/jhnj

\section{Let us know how access to this document benefits you}

\section{Recommended Citation}

Shoukat, MD, Umer; Mukhtar, MD, Umer; and Athar, MD, M. Kamran (2016) "Managing Hyperglycemia in Critically Ill Patients: Where are We Now?," JHN Journal: Vol. 11 : Iss. 1 , Article 3.

DOI: https://doi.org/10.29046/JHNJ.011.1.003

Available at: https://jdc.jefferson.edu/jhnj/vol11/iss1/3

This Article is brought to you for free and open access by the Jefferson Digital Commons. The Jefferson Digital Commons is a service of Thomas Jefferson University's Center for Teaching and Learning (CTL). The Commons is a showcase for Jefferson books and journals, peer-reviewed scholarly publications, unique historical collections from the University archives, and teaching tools. The Jefferson Digital Commons allows researchers and interested readers anywhere in the world to learn about and keep up to date with Jefferson scholarship. This article has been accepted for inclusion in JHN Journal by an authorized administrator of the Jefferson Digital Commons. For more information, please contact: JeffersonDigitalCommons@jefferson.edu. 


\section{Managing Hyperglycemia in Critically Ill Patients: Where Are We Now?}

\author{
Umer Shoukat, $M D^{1,2} ;$ Umer Mukhtar, $M D^{1,2} ; M$. Kamran Athar, $M D^{1,2}$ \\ ${ }^{1}$ Department of Neurology, Thomas Jefferson University, Philadelphia,PA \\ ${ }^{2}$ Department of Neurological Surgery, Thomas Jefferson University, Philadelphia,PA
}

Hyperglycemia is common in critically ill patients and is associated with increased morbidity, mortality, rate of infections and length of hospital stay. For decades, hyperglycemia in critically ill population was considered an adaptive response and interventions were only considered if diabetic ketoacidosis (DKA) or severe hyperosmolar states developed. Furnary et al published studies showing lower sternal wound infection rates in cardiac surgical patients with control of glucose (180-220 mg/dl). This led to the dissemination of the "Portland Protocol," but it was not widely accepted. ${ }^{1,2}$

Management of hyperglycemia changed with the publication of Van Den Berghe study. ${ }^{3}$ This was a prospective, randomized, controlled study involving adults admitted to a surgical intensive care unit (ICU) who were receiving mechanical ventilation (MV). A total of 1548 patients were enrolled with patients randomly assigned to two groups. One group received intensive insulin therapy (IIT) with goal blood glucose of 80-110 $\mathrm{mg} / \mathrm{dl}$. The second group received conventional treatment whereby insulin was given only if the blood glucose level exceeded $215 \mathrm{mg} / \mathrm{dl}$ with goal glucose level of 180-200 $\mathrm{mg} / \mathrm{dl}$.

The primary outcome measure was death from any cause during intensive care. The main secondary outcome measures were in-hospital death; the number of days in the intensive care unit and the need for prolonged intensive care (more than 14 days) or readmission; the need for ventilatory support, renal replacement therapy, or inotropic or vasopressor support. At 12 months, IIT reduced mortality during intensive care from $8.0 \%$ with conventional treatment to $4.6 \%(P<0.04)$ in intensive treatment group. The benefit of intensive insulin therapy was attributable to its effect on mortality among patients who remained in the intensive care unit for more than five days $(20.2 \%$ with conventional treatment, as compared with $10.6 \%$ with IIT; $\mathrm{P}=0.005)$. The greatest reduction in mortality involved deaths due to multiple-organ failure with a proven septic focus. IIT also reduced overall in-hospital mortality by $34 \%$.

Subsequently, in another single center study, ${ }^{4}$ Van Den Berghe randomly assigned 1200 patients in medical ICU to strict normalization of blood glucose levels $(80-110 \mathrm{mg} / \mathrm{dl}$ ) with the use of insulin infusion or to conventional therapy. The study showed no significant difference in hospital mortality $40.0 \%$ in the conventional-treatment group vs. $37.3 \%$ in the intensive-treatment group, $p=0.33$ ). However, IIT reduced morbidity and mortality in patients that stayed in ICU for three or more days. The reasons for reduced morbidity in patients who received IIT were the prevention of acquired kidney injury, earlier weaning from MV, and earlier discharge from the medical ICU and hospital.

A number of multicenter studies were performed following the initial Van Den Berghe trial in an attempt to replicate the earlier results. VISEP (Volume Substitution and Insulin Therapy in Severe Sepsis) study ${ }^{5}$ and Glucocontrol study ${ }^{6}$ were prospective, multicenter randomized control trials whereas Wiener study ${ }^{7}$ was a meta-analysis of 29 randomized controlled trials having a total of 8432 patients. The results of these studies showed no significant difference in mortality in the conventional and tight control groups but increased episodes of severe hypoglycemia.
Given the conflicting data regarding tight glycemic control, the NICE-SUGAR study ${ }^{8}$ was undertaken. This was a multicenter randomized control trial which enrolled 6104 patients. Study compared intensive target glucose of 80 to $108 \mathrm{mg} /$ $\mathrm{dl}$ to the conventional target of $180 \mathrm{mg} /$ dl or less.

Primary outcome was death from any cause within 90 days after randomization. Secondary outcomes were survival in first 90 days, cause-specific death, duration of MV, length of stay in the ICU, and total length of stay in the hospital. The intervention was discontinued when patients were discharged from ICU or eating and were resumed if the patient was readmitted within 90 days. Blood glucose $<40 \mathrm{mg} / \mathrm{dl}$ was considered a serious adverse event. One-third of the patients were surgical patients and twothirds were medical patients. Mortality in intensive target group was 27.5\% compared to $24.9 \%$ in conventional group ( $p=0.02)$. The incidence of severe hypoglycemia ( $<40 \mathrm{mg} / \mathrm{dl}$ ) was $6.8 \%$ in intensive group compared with $0.5 \%$ in conventional group $(p<0.001)$.

There were a number of differences between Van Den Berghe trial and NICESUGAR trial, which may help explain their divergent results. Van Den Berghe study was performed at a single center and considered reduction of glucose level only if it was markedly elevated (>215 $\mathrm{mg} / \mathrm{dl}$ ). In contrast, NICE-SUGAR study was multinational and the glucose level in conventional group was targeted at only a mildly elevated range of 144 to $180 \mathrm{mg} / \mathrm{dl}$. Most patients in Van Den Berghe trial received parenteral nutrition whereas enteral nutrition was the rule in NICE-SUGAR study. 
The strengths of NICE trial include its large, multicenter patient population, vigorous statistical analysis and broad representative spectrum of critically ill patients. However, some of the downfalls were open-label study design and premature discontinuation of treatment in $10 \%$ of the patients. Increased risk of death from IIT in NICE-SUGAR study can be attributed to multiple factors including direct harmful effects of insulin and neuroglycopenia that warrants further studies. ${ }^{9}$

An summary, IIT seems to save lives in the initial Van Der Berghe trial but its results are yet to be replicated, particularly in any multicenter trial. Critical care and endocrinologic societies have backed away from recommending intensive insulin therapy. ADA/AACE Inpatient Task Force recommends that insulin infusion should be used to control hyperglycemia with the starting threshold of $180 \mathrm{mg} / \mathrm{dl}$. Once IV insulin is started, the target glucose is between 140 and $180 \mathrm{mg} / \mathrm{dl}$. Lower glucose targets (110-140 mg/dl) may be appropriate in selected patients. Targets $<110 \mathrm{mg} / \mathrm{dl}$ are not recommended. ${ }^{10}$

\section{HYPERGLYCEMIA IN BRAIN INJURED PATIENTS}

Hyperglycemia is a common secondary insult in traumatic brain injury (TBI), subarachnoid hemorrhage (SAH), and acute ischemic stroke and has been consistently associated with poor neurological outcome. ${ }^{11}$

\section{ISCHEMIC STROKE}

Several studies have evaluated the effect of IIT in acute ischemic stroke patients with hyperglycemia. ${ }^{12,13}$ UK Glucose Insulin in Stroke Trial was the largest randomized clinical trial, which enrolled 933 patients and showed no clinical benefit of IIT. ${ }^{14}$

INSULINFARCT trial randomized 180 patients with acute stroke to receive IIT or subcutaneous insulin treatment during the first 24 h. ${ }^{15}$ It demonstrated that IIT in the first $24 \mathrm{~h}$ was associated with larger infarct growth and was not recommended.

\begin{tabular}{|c|c|c|c|}
\hline Study & IIT (\%) & Conventional (\%) & $p$ value \\
\hline Van Den Berghe (2001) & 4.6 & 8 & $<0.04$ \\
\hline Van Den Berghe (2006) & 37.3 & 40 & 0.33 \\
\hline VISEP (2008) (At 28 days) & 24.7 & 26 & 0.74 \\
\hline Glucocontrol (2009) (At 28 days) & 18.7 & 15.3 & 0.14 \\
\hline NICE-SUGAR (2009) & 27.5 & 24.9 & 0.02 \\
\hline
\end{tabular}

\begin{tabular}{|c|c|c|c|}
\hline Hypoglycemia & & & \\
\hline Study & IIT (\%) & Conventional (\%) & $p$ value \\
\hline VISEP (2008) & 17 & 4.1 & $<0.001$ \\
\hline NICE-SUGAR (2009) & 6.8 & 0.5 & $<0.001$ \\
\hline Glucocontrol (2009) & 8.7 & 2.7 & $<0.0001$ \\
\hline
\end{tabular}

\begin{tabular}{|c|c|c|c|}
\hline Sample Size & & & \\
\hline Study & n (Total) & n (Conventional) & n (IIT) \\
\hline Van Den Berghe (2001) & 1548 & 783 & 765 \\
\hline Van Den Berghe (2006) & 1200 & 605 & 595 \\
\hline VISEP (2008) & 537 & 290 & 247 \\
\hline Glucocontrol (2009) & 1101 & 551 & 550 \\
\hline NICE-SUGAR & 6104 & 3050 & 3054 \\
\hline
\end{tabular}


AHA/ASA recommends that it is reasonable to treat hyperglycemia to achieve blood glucose levels in a range of 140 to $180 \mathrm{mg} / \mathrm{dl}$ and to closely monitor to prevent hypoglycemia in patients with acute ischemic stroke ${ }^{16}$ (Class II a; Level of Evidence C).

\section{SUBARACHNOID HEMORRHAGE}

Hyperglycemia may have detrimental effects in patients with subarachnoid hemorrahge by increasing chances of infection, cerebral ischemia and by facilitating the progression from ischemia to irreversible infarction.

The majority of the studies using IIT reported episodes of hypoglycemia. Insulin therapy inducing episodes of low glucose was associated with cerebral infarction, vasospasm, and worse functional outcome 3 months following $\mathrm{SAH} .{ }^{17}$ There is only one randomized trial where 40 patients receive IIT. This study showed no significant improvement in clinical outcome or the incidence of vasospasm. ${ }^{18}$

Currently there is no evidence that hyperglycemia in $\mathrm{SAH}$ patients should be treated with IIT. This treatment is accompanied by an increase in hypoglycemic episodes.

AHA/ASA recommends that glucose management with strict avoidance of hypoglycemia may be considered as part of the general critical care management of patients with Aneurysmal $\mathrm{SAH}^{19}$ (Class Ilb; Level of Evidence B).

\section{TRAUMATIC BRAIN INJURY}

Hyperglycemia contributes to poor outcome in TBI patients. Hyperglycemia has been shown to worsen ischemic brain injury in experimental studies with animals. One study analyzing cortical contusion injury in rats found that hyperglycemia worsens the injury with superimposed ischemia. ${ }^{20}$ In two class III human studies, hyperglycemia has been associated with worsened outcome. ${ }^{21,22}$ A randomized controlled trial of 97 patients with severe $\mathrm{TBI}$ compared a regimen of IIT versus conventional management. No significant differences were observed in mortality and poor functional outcome at 6 months.
Meanwhile, the incidence of hypoglycemic events was markedly increased among patients treated with IIT.23 This was confirmed in an additional randomized trial with total of 523 patients including $94 \mathrm{TBI}$ patients. IIT was not associated with improved survival and was associated with increased occurrence of hypoglycemia. ${ }^{24}$

Current clinical trials do not show any benefit of tight glucose control with IIT in TBI patients with increased episodes of hypoglycemia. ${ }^{25}$

\section{CONCLUSION}

In summary, significant body of literature has shown that hyperglycemia is common in patients with TBI, SAH, and ischemic stroke and that it is related to poor outcome. However, no concrete evidence exists that tight glycemic control improves outcome in these patients. It might on the contrary lead to hypoglycemic episode with deleterious effects on the injured brain due to secondary neuronal injury.

\section{REFERENCES}

1. Zerr KJ, Furnary AP, Grunkemeier GL, et al. Glucose control lowers the risk of wound infection in diabetics after open heart operations. Ann Thorac Surg. 1997 Feb; 63(2): 356-61.

2. Furnary AP, Zerr KJ, Grunkemeier GL, et al. Continuous intravenous insulin infusion reduces the incidence of deep sternal wound infection in diabetic patients after cardiac surgical procedures. Ann Thorac Surg. 1999 Feb; 67(2): 352-60.

3. Van den Berghe G, Wouters P, Weekers F, et al. Intensive insulin therapy in critically ill patients. N Engl J Med. 2001 Nov 8; 345(19): 1359-67.

4. Van Den Berghe G, Wilmer A, Hermans G, et al. Intensive insulin therapy in the medical ICU. N Engl J Med. 2006 Feb 2; 354(5): 449-61.

5. 5. Brunkhorst FM, Engel C, Bloos F, MeierHellmann A, et al. Intensive insulin therapy and pentastarch resuscitation in severe sepsis N Engl J Med. 2008 Jan 10; 358(2): 125-39.

6. Preiser JC, Devos P, Ruiz-Santana S, et al. A prospective randomised multi-centre controlled trial on tight glucose control by intensive insulin therapy in adult intensive care units: the Glucontrol study. Intensive Care Med. 2009 Oct; 35(10): 1738-48.
7. Wiener RS, Wiener DC, and Larson RJ Benefits and risks of tight glucose control in critically ill adults: a meta-analysis. JAMA. 2008 Aug 27; 300(8): 933-44

8. 8. Finfer $S$, Chittock DR, Su SY, et al. Intensive versus conventional glucose control in critically ill patients. N Engl J Med. 2009 Mar 26: 360(13): 1283-97.

9. Inzucchi SE, and Siegel. Glucose control in the ICU--how tight is too tight? N Engl J Med. 2009 Mar 26; 360(13): 1346-9

10. Connolly ES Jr, Rabinstein AA, Carhuapoma JR, et al. Guidelines for the management of aneurysmal subarachnoid hemorrhage: a guideline for healthcare professionals from the American Heart Association/american Stroke Association. Stroke 2012 Jun; 43(6): 1711-37.

11. Rostami E. Glucose and the injured brainmonitored in the neurointensive care unit Front Neurol. 2014 Jun 6; 5: 91.

12. Candelise L, Landi G, Orazio EN, et al. Prognostic significance of hyperglycemia in acute stroke. Arch Neurol. 1985 Jul; 42(7): 661-3.

13. Bruno A1, Biller J, Adams HP Jr, et al. Acute blood glucose level and outcome from ischemic stroke. Trial of ORG 10172 in Acute Stroke Treatment (TOAST) Investigators. Neurology. 1999 Jan 16; 52(2): 280-4.

14. Gray CS1, Hildreth AJ, Sandercock PA, et al. Glucose-potassium-insulin infusions in the management of post-stroke hyperglycaemia: the UK Glucose Insulin in Stroke Trial (GISTUK). Lancet Neurol. 2007 May; 6 (5): 397-406

15. Rosso C, Corvol JC, Pires $C$ et al. Intensive versus subcutaneous insulin in patients with hyperacute stroke: results from the randomized INSULINFARCT trial. Stroke. 2012 Sep; 43(9): 2343-9.

16. Jauch EC, Saver JL, Adams HP Jr, et al. Guidelines for the early management of patients with acute ischemic stroke: a guideline for healthcare professionals from the American Heart Association/American Stroke Association. Stroke 2013 Mar; 44(3): 870-947.

17. Naidech AM, Levasseur $K$, Liebling $S$, et al. Moderate Hypoglycemia is associated with vasospasm, cerebral infarction, and 3-month disability after subarachnoid hemorrhage. Neurocrit Care. 2010 Apr; 12(2): 181-7.

18. Bilotta F, Spinelli A, Giovannini F, et al. The effect of intensive insulin therapy on infection rate, vasospasm, neurologic outcome and mortality in neurointensive care unit after intracranial aneurysm clipping in patients with acute subarachnoid hemorrhage: a randomized prospective pilot trial. J Neurosurg Anesthesiol. $2007 \mathrm{Jul}$; 19(3): 156-60.

19. Handelsman $Y$, Bloomgarden ZT, Grunberger $G$, et al. American association of clinical endocrinologists and american college of endocrinology - clinical practice guidelines for developing a diabetes mellitus comprehensive care plan - 2015. Endocr Pract. 2015 Apr 1; 21(0): 1-87. 
20. Cherian L., Goodman JC, Robertson CS

Hyperglycemia increases brain injury caused by secondary ischemia after cortical impact injury in rats. Crit Care Med 1997; 25: 13781383.

21. Lam AM, Winn HR, Cullen BF, et al.

Hyperglycemia and neurological outcome in patients with head injury. J Neurosurg 1991;75:545-551.

22. Young B, Ott L, Dempsey R, et al. Relationship between admission hyperglycemia and neurologic outcome of severely brain-injured patients. Ann Surg 1989;210:466-473.

23. Bilotta F, Caramia R, Cernak I, Paoloni FP, Doronzio A, Cuzzone V, et al. Intensive insulin therapy after severe traumatic brain injury: a randomized clinical trial. Neurocrit Care (2008) 9:159-66.doi:10.1007/s12028-0089084-9

24. Arabi YM, Dabbagh OC, Tamim HM, et al. Intensive versus conventional insulin therapy: a randomized controlled trial in medical and surgical critically ill patients. Crit Care Med. 2008 Dec; 36(12): 3190-7.

25. Marion DW. Optimum serum glucose levels for patients with severe traumatic brain injury F1000 Med Rep. 2009 May 28; 1.

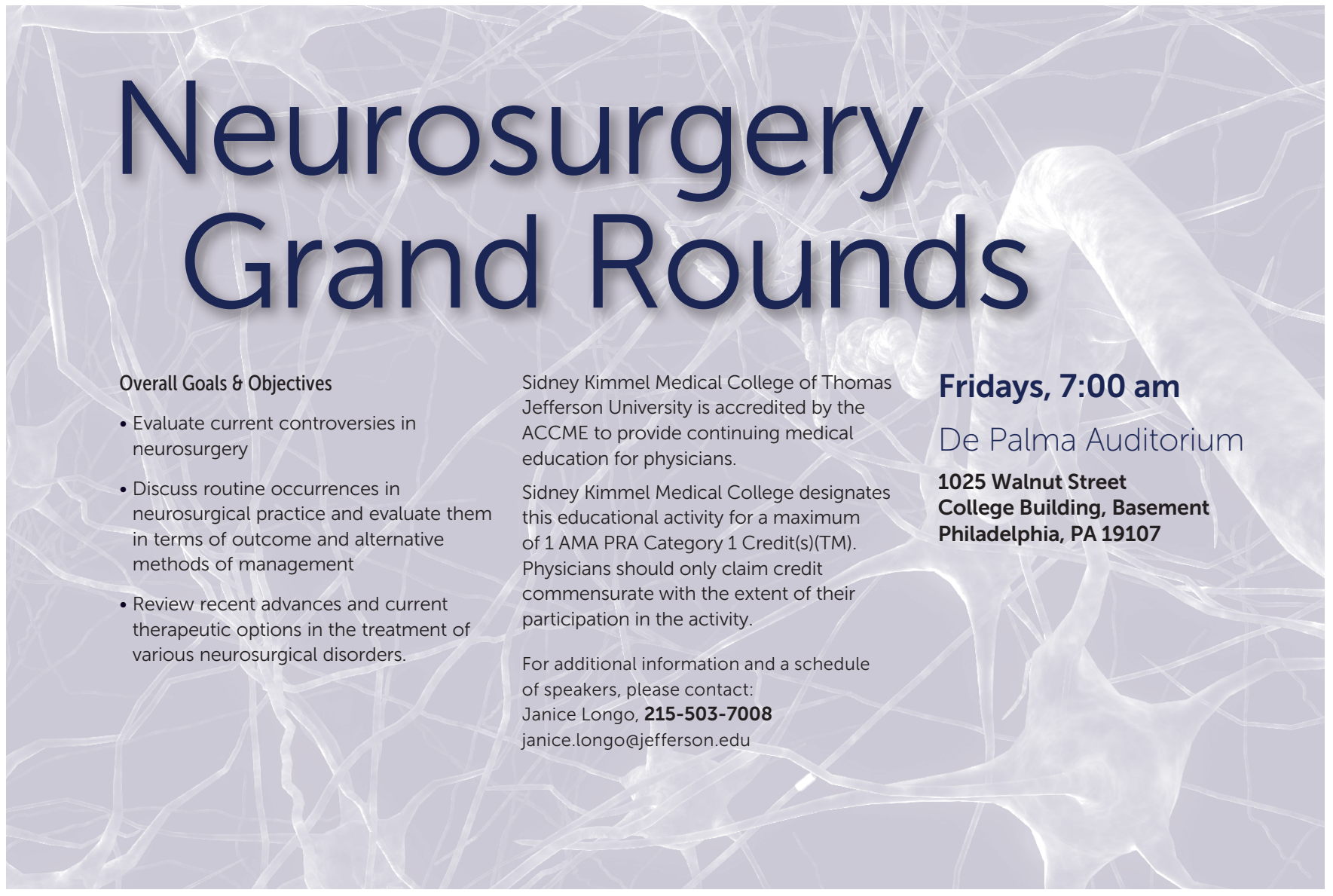

